\title{
Gender in Disaster Mitigation
}

\author{
Ridha Marissa El Seira ${ }^{1, *}$ Euis Kurniati ${ }^{1}$
}

\author{
${ }^{1}$ Department of Early Childhood Education, School of Postgraduate Studies, Universitas Pendidikan Indonesia, \\ Bandung, Indonesia \\ *Corresponding author. Email: ridhamarissa@upi.edu
}

\begin{abstract}
Indonesia is one of the countries that is easily affected by natural disasters. Previous research has been focusing on the disaster mitigation, including on the post-trauma counseling for the victims. This paper aims to explore under-research area by exploring how disaster mitigation responds to the need of young children. Using a feminist lens, this paper would explore what extent the disaster mitigation has been adopting gender responsive principle. Using a literature review, this paper also aims to see whether or not the existing mitigation approach has in fact potentially harmed one gender. Finding of this paper is expected to offer recommendation to policy makers and educators on how to develop a gender responsive and also gender equity mitigation approach.
\end{abstract}

Keywords: Gender, disaster, mitigation

\section{INTRODUCTION}

Indonesia is one of the countries that is prone to disaster. There are a total of 2,190 disasters which occurred from 1 January 2019 to 30 September 2019 (Badan Nasional Penanggulangan Bencana, 2019). The victims from the disasters are mainly children, women, and elderly, which are included in the vulnerable population (Lopez, Hayden, Cologon, \& Hadley, 2012; Pillai \& Sekar, 2013; Alston et al., 2019).

Existing disaster studies often categorize children based on age and sex. This makes the role of gender, responsibility, and social norms become neglected (Washington, 2018). Previous research studies review that women are often considered into a marginal group (The National Academics, 2012; Daramola, Oni, Ogundele, \& Adesanya, 2016; Akerkar \& Fordham, 2017; Cvetkovi Roder, Öcal, \& Tarolli, 2018; Hemachandra, Amaratunga, \& Haigh, 2018; Kaban et al., 2019). However, those studies could not show disaster analysis through the perspective of gender. Gender in the context of disaster is often regarded equal to biological sex. This study uses post-structuralist feminist lens, which is a movement to end sexism, sexist exploitation, and oppression (Hooks, 2000). This study is done based on literature review of eight credible research studies, conducted in order to see whether existing disaster mitigations already contain the principles of gender responsiveness. The aim of this paper is also to explore disaster mitigation approaches that may have the potential to harm one exclusive gender.

Government officials from several countries, including Indonesia, have started to include gender and children discussion in disaster mitigation efforts (Cutter, 2017; Cvetkovi Roder et al., 2018). However, many disaster experts are seemed to be immersed in social construction by only seeing sex as a determinant of gender in disaster situations and giving little to no role for children in contexts of disaster.

Thus, the research attempts to bridge the existing gaps by exploring the extent of gender responsiveness in disaster mitigation. Specifically, this study attempts to explore existing mitigation approaches that may have the potential to harm one exclusive gender in post-disaster situations.

\section{LITERATURE REVIEW}

This study uses post-structuralist feminist lens, which explores the existence of gender in disaster mitigation. Gender is often misinterpreted as having the same definition as biological sex. In fact, gender itself has two interrelated components, which are constitutional element of social relations based on perceived differences and the main way to signify the existence power relations (Wooldridge, 2015). Gender is not merely about physical differences, but also about social construct regarding masculinity and femininity circulated in the community. In post-structuralist feminist study, social construct is built on the basis of social beliefs in the discourse of gender construction, which is subconsciously accepted through a process of normalization (Wooldridge, 2015). Normalization leads one particular discourse believed and creates a stereotype that is inherent in a community. Not only in the form of stereotype, laws and constitutional regulation imposed in an area, built with the agreement of said community, is also a normalization tool which could effectively instill a particular discourse in the community. In post-structuralist perspective, the existence of gender is an important element in the creation of disaster mitigation 
in a community. Gender is often related to an individual's identity through biological discourse (Akbar \& Witruk, 2016; Young, Greenbaum, \& Dormady, 2017). Meanwhile, the stereotypes of gender roles circulated in a community is built with the basis of social and economy discourse which shows gender roles in a specific area (Banford \& Froude, 2015; Akerkar \& Fordham, 2017). It is also traditional discourse which instills access from gender to the society (Reyes \& Lu, 2015; Chineka, Musyoki, Kori, \& Chikoore, 2019). Gender-inclusive discourses in the context of disasters could create gender participation in disaster mitigation (Thapa \& Pathranarakul, 2019). Disaster contexts also include political discourse that related to gender identity in a community (Hasan, Nasreen, \& Chowdhury, 2019).

Apart from the social construction of a community which sees masculinity and femininity as the same thing as male and female, there is also the existence of power relation between the two. The hegemony of masculinity holds a strong role in a patriarchal society (Fernández-Álvarez, 2014). When a society perceives masculinity as a more dominant role than femininity, it demands male individuals to have more masculinity than their female counterparts. Males are perceived as a strong individual who can protect females. Meanwhile, females, who are seen as someone who should have higher femininity, are people who play a gentle role, someone who should be protected and having little to no domination in disaster situations.

Through post-structuralist feminist perspective, this paper attempts to show how discourse is built in a disaster mitigation in the perspective of gender. The society's belief regarding what is perceived true between the role of male and female is a discourse that creates power over the gender definition itself. The domination of masculinity in patriarchal culture then should be more convincingly emerged in a society regarding gender position. However, the discourse of the hegemony itself is believed to be more dominant and is considered to be true than any other discourses.

\section{METHOD}

This study uses post-structuralist feminist lens, which is a movement to end sexism, sexist exploitation, and oppression (Hooks, 2000). This study is based on a literature review of eight credible journals, conducted to see whether existing disaster mitigation approaches have included principles of gender responsiveness. This study also aims to explore disaster mitigation approaches that may have potentials to harm one exclusive gender.

\section{DISCUSSION}

Literature on gender and disaster mitigation comes from various multi-disciplinaries. Through post-structuralist feminist perspective, this paper attempts to question society paradigm regarding gender role in disasters. Over the past few years, there is a shift in paradigm, in which now it considers gender perspective in disaster mitigation. Starting from this, the analysis obtained continues with how gender discourse exists in disaster mitigation, as well as how power relations built from the discourse applied so that it causes violence and vulnerability in disaster mitigation, which may have a tendency to harm one exclusive gender.

\subsection{Discourse in Disaster Mitigation}

Disaster mitigation would never be separated from gender. Gender is constructed from various discourses regulated in society. Gender is often related to an individual's identity through physical and biological forms. Gender is both a process and differences that is socially constructed, meanwhile sex is defined as a physical characteristic in order to differentiate male and female (Rushton, Gray, Canty, \& Blanchard, 2019).

Female is considered as a group who has the possibility to experience higher stress level, but also has a faster coping mechanism strategy (Akbar \& Witruk, 2016). It is considered so due to an idea that female thinks too much and could not handle post-disaster traumas that they have experienced. Past experiences are limited to seeing disaster mitigation through gender perspective in the sense of sex. Meanwhile, in a resiliency process, the role of sex is relatively less influential than the role of gender with feminine attributes itself (Young et al., 2017).

There exists traditional discourse which built gender discourse in a form of stereotypes in disaster mitigations (Banford \& Froude, 2015; Akerkar \& Fordham, 2017; Chineka et al., 2019). Patriarchy dominance in a society (Thapa \& Pathranarakul, 2019) could create difficulties for women to be given a responsibility in decision-making positions (Hemachandra et al., 2018). Women would assume domestic roles, meanwhile the social construction in traditional society would be relatively dominated by men. Only a handful of people affiliated with NonGovernmental Organizations (NGOs) and political parties are aware of gender equality, and women and human rights (Reyes \& Lu, 2015).

One of the main factors in why women and children are included in vulnerable populations is due to lack of access and opportunities (Thapa \& Pathranarakul, 2019), based on culture, social, and position of the individuals in the society (Becker, 2011; Hemachandra et al., 2018; Thapa \& Pathranarakul, 2019). Most men would disagree and object 
in the idea of women being given a role in disaster situations (Enarson \& Chakrabarti, 2009; Thapa \& Pathranarakul, 2019; Hasan et al., 2019)

The belief of religion discourse also affects the limits and roles of women in social structures, household burdens, education, interests, policies and legislations, organizational culture, political environment, and household income (Enarson \& Chakrabarti, 2009; Hemachandra et al., 2018; Hasan et al., 2019). Meanwhile, gender-based dichotomy in disaster mitigation has been socially normalized, especially in politics which then gives a better predicate to masculinity (Wooldridge, 2015).

Based on the explanation of the discussion result regarding discourses in disaster mitigation, there are two topics which emerged from said discourses. The first one is the categorization of children based on sex between female and male. The second one is the categorization of dominating group and marginalized group.

\subsection{Violence in Disaster Mitigation}

Disaster causes various violence forms as its own impact. However, violence in the framework of post-structuralist is not an intrinsic part of human condition, but rather an aspect legitimized by social processes (Wooldridge, 2015). The violence intended to be discussed is not physical violence, but rather something that would prevent someone to realize their own potential. This violence then normalized and subconsciously accepted by the society.

There are three types of violence in disaster mitigation. The first type is a direct violence in the form of physical violence. Then the next one is a structural violence, such as someone's death as a result of the lack of health access. The last type is a cultural violence, which acts through discourses, ideologies, and religions serving to normalize structural violence (deaths due to the lack of health access).

Violence forms which are not characterized with physical attacks are often disregarded by the society. It may happen due to social policies and government roles which evoke structural violence, making it normalized and accepted by the society. Structural violence would occur when there is a lack of coordination between the government, departments, and local communities; lack of data processing on disasters; instability in system regulation; lack of funding; lack of monitoring; incomplete disaster policies; lack of inclusivity, transparency, and timely manner in government policies; leading to difficulties in the realization of a gender responsive disaster mitigation (Hemachandra et al., 2018; Thapa \& Pathranarakul, 2019). It is also true that violence does not always occur from the governmental aspect. It is supported by the idea that power is not merely the subject, but rather a relation between the power itself and science (Foucault, 2002). On the case of disaster mitigation, power comes from a discourse that has been legitimized by social structures regulated in the society. Social structure in the community puts masculinity in a dominating role between the genders. Society would see that men should have higher masculinity than women. They also deem that men should be able to protect women, meanwhile women with their femininity would be considered as a marginalized group that has little to no role in disaster mitigation (Reyes \& Lu, 2015).

Gender analyses reveal that women in a patriarchal society are disadvantageous in the term of social, economy, and politic, especially those who come from a lower social class (Yumarni, Amaratunga, \& Haigh, 2014). Therefore, a traditionally constructed gender role would affect the impact of disaster in femininity and masculinity in a society. We should consider the way in which we built different gender roles creates different risks for men and women in disaster situations, and how we plan it, by avoiding assumptions that men with their masculinity would be tougher than women with their femininity (Thapa \& Pathranarakul, 2019).

With a marginalized femininity in a society and a masculine dominance, women that are considered vulnerable population would become more vulnerable in disasters due to the fact that they would face greater risks of disaster. By focusing on social construction (Banford \& Froude, 2015) it is understood that women vulnerability is increased after a disaster happened. The society stereotype that characterized by prioritizing patriarchy (Baugher \& Gazmararian, 2015) creates a clearer gender gap in a postdisaster situation.

In general, direct violence that occurs in a disaster-related situation, including harassment and gender-sensitive issues, has been investigated through various researches (Akhter et al., 2015; Cutter, 2017). When a disaster occurs, children and women have increased violence risks, decrease in private spaces by sharing public rooms with strangers, pressures and physical violence including sexual harassment, isolated feelings and regrets (Spindler, Elklit, \& Christiansen, 2010; Ginige, Amaratunga, \& Haigh, 2014; Yumarni et al., 2014; Nguyen \& Rydstrom, 2018; Hasan et al., 2019; Thapa \& Pathranarakul, 2019).

Cultural violence also occurs in disaster mitigation. When religion discourse reveals that women play a household role while men are responsible for earning a living, it shows that masculinity has a dominance in gender role regarding decision-making position (Hasan et al., 2019). Cultural discourse also has a role in the form of the exposure of cultural violence in disasters (Becker, 2011). The culture of patriarchy that still exists in disaster mitigation affects disaster risk in the perspective of gender. Patriarchal culture considers that women are generally seen as more risk aversive and men would be more tolerant to risk (Becker, 2011). 
In fact, the difficulties that occurred are intentional. Discourses around disaster mitigation create a perspective in the society that would harm certain groups while protecting the others (Banford \& Froude, 2015). It leads to the opportunity of creating gender gaps, as shown from the lack of the recognition of femininity roles in the context of disaster, which further marginalized said femininity. In fact, women with femininity hold many roles and responsibilities before, during, and after disasters (Akhter et al., 2015).

The statement above can be supported by highlighting the feminine quality from women, which would better represent a mother's warmth and their capability of comforting someone affected by disasters more effectively than men (Young et al., 2017; Hemachandra et al., 2018). However, women and children's important role is often not recognized and has limited space in society (Lopez et al., 2012; Hemachandra et al., 2018; Alston et al., 2019). It opens the higher possibility in the increase of violence and sexual harassment in women, and increases their vulnerability in disasters.

From the explanations explored above, it is revealed how gender discourse would have an important role in disaster mitigation. Discourse could create a power relation in society, where femininity and masculinity are then further defined in community, then further grouped masculinity into a dominant group while marginalizing femininity. There would also be seen how discourse in the society shapes the violence that occurs in disaster mitigation. Analyses of structural and cultural violence, and any other direct form of violence occurs before, during, and after disasters should be prepared and done as an effort to improve a more gender responsive disaster mitigation program (Nguyen \& Rydstrom, 2018).

\section{CONCLUSION}

Disaster mitigation is a large space for a discourse in the society. Discourses built in the society, along with their stereotypes, reveal how masculinity is given a more dominant role while marginalizing femininity. Discourses in disaster mitigation need to be considered due to the fact that it ignores the dynamics of power relation between genders, assuming that masculinity holds a more powerful position than femininity. This condition subconsciously considered as something usual for the fact that it is normalized by social system, which in turns giving a more powerful belief of a masculinity dominancy in society.

The result and discussion that have been explained reveal that gender perspective in disaster mitigation needs to be recognized and understood. Previous studies show that women and men, with their masculinity and femininity, have different ways of thinking, experiencing, and adapting into situations in disaster mitigation programs.
Thus, government needs to draw up a policy regarding disaster mitigation that does not lean towards one specific gender. It can be seen from the reality that how access and power in disaster mitigation is, in fact, leaning towards one specific gender and marginalizing other groups, which later creating hurdles in disaster mitigation. Thus, it can be said that government should focus on approaches that can be negotiated and compromised with a more genderresponsive disaster mitigation.

\section{ACKNOWLEDGMENT}

The authors would like to acknowledge Indonesia Ministry of Education and Culture for International Conference on Early Childhood Education and Parenting 2019. As well as to authors' colleagues for genuine guidance to providing with the much needed information for completing this paper.

\section{REFERENCES}

Akbar, Z., \& Witruk, E. (2016). Coping mediates the relationship between gender and posttraumatic growth. Procedia- Social and Behavioral Sciences, 217, 10361043. doi:https://doi.org/10.1016/j.sbspro.2016.02.102

Akerkar, S., \& Fordham, M. (2017). Gender, place and mental health recovery in disasters: Addressing issues of equality and difference. International Journal of Disaster Risk Reduction, 23, 218-230. doi:https://doi.org/10.1016/j.ijdrr.2017.03.014

Akhter, S. R., Sarkar, R. K., Dutta, M., Khanom, R., Akter, N., Chowdhury, M. R., \& Sultan, M. (2015). Issues with families and children in a disaster context: A qualitative perspective from rural Bangladesh. International Journal of Disaster Risk Reduction, 13, 313-323. doi:https://doi.org/10.1016/j.ijdrr.2015.07.011

Alston, M., Hazeleger, T., Hargreaves, D., Alston, M., Hazeleger, T., \& Hargreaves, D. (2019). Gender and disasters. Social Work and Disasters, 181-197. doi:https://doi.org/10.4324/9781315109138-11

Badan Nasional Penanggulangan Bencana. (2019). Jumlah kejadian 2019. Retrieved September 28, 2019, from https://bnpb.cloud/dibi//

Banford, A., \& Froude, C. K. (2015). Ecofeminism and natural disasters: Sri Lankan women post-tsunami. Journal of International Women's Studies, 16(2), 170187. 
Baugher, A. R., \& Gazmararian, J. A. (2015). Masculine gender role stress and violence: A literature review and future directions. Aggression and Violent Behavior, 24, 1-25.

doi:https://doi.org/10.1016/j.avb.2015.04.002

Becker, P. (2011). Whose risks? Gender and the ranking of hazards. Disaster Prevention and Management, 20(4), 1-12. doi:https://doi.org/10.1108/09653561111161743

Chineka, J., Musyoki, A., Kori, E., \& Chikoore, H. (2019). Gender mainstreaming: A lasting solution to disaster risk reduction. Jàmbá: Journal of Disaster Risk Studies, 11(3), 1-6.

doi:https://doi.org/10.4102/jamba.v11i3.723

Cutter, S. L. (2017). The forgotten casualties redux: Women, children, and disaster risk. Global Environmental Change, 42, 117-121. doi:https://doi.org/10.1016/j.gloenvcha.2016.12.010

Cvetkovi, V. M., Roder, G., Öcal, A., \& Tarolli, P. (2018). The role of gender in preparedness and response behaviors towards flood risk in serbia. International Journal of Environmental Research and Public Health, 15, 1-21. doi:https://doi.org/10.3390/ijerph15122761

Daramola, A. Y., Oni, O. T., Ogundele, O., \& Adesanya, A. (2016). Adaptive capacity and coping response strategies to natural disasters: A study in Nigeria. International Journal of Disaster Risk Reduction, 15, 132-147. doi:https://doi.org/10.1016/j.ijdrr.2016.01.007

Enarson, E., \& Chakrabarti, P. G. D. (2009). Women, gender, and disaster. India: SAGE Publiations.

Fernández-Álvarez, Ó. (2014). Non-Hegemonic Masculinity against Gender Violence. Procedia- Social and Behavioral Sciences, 161, 48-55.

doi:https://doi.org/10.1016/j.sbspro.2014.12.009

Foucault, M. (2002). The order of things: An archaeology of the human sciences. New York: Routledge.

Ginige, K., Amaratunga, D., \& Haigh, R. (2014). Tackling Women's Vulnerabilities through Integrating a Gender Perspective into Disaster Risk Reduction in the Built Environment. Procedia Economics and Finance, 18, 327-335. doi:https://doi.org/10.1016/s2212-5671(14)00947-2

Hasan, M. R., Nasreen, M., \& Chowdhury, M. A. (2019). Gender-inclusive disaster management policy in
Bangladesh: A content analysis of national and international regulatory frameworks. International Journal of Disaster Risk Reduction, 101324. doi:https://doi.org/10.1016/j.ijdrr.2019.101324

Hemachandra, K., Amaratunga, D., \& Haigh, R. (2018). Role of women in disaster risk governance. Procedia Engineering, 212, 1187-1194. doi:https://doi.org/10.1016/j.proeng.2018.01.153

Hooks, B. (2000). Feminism is for everybody: In planning. Canada: South End Press.

Kaban, P. A., Kurniawan, R., Caraka, R. E., Pardamean, B., Yuniarto, B., \& Sukim. (2019). Biclustering method to capture the spatial pattern and to identify biclustering method to capture the spatial pattern and to identify the causes of social vulnerability in Indonesia: A New the Causes of Social Vulnerability in Indonesia: A new recommend. Procedia Computer Science, 157, 31-37. doi:https://doi.org/10.1016/j.procs.2019.08.138

Lopez, Y., Hayden, J., Cologon, K., \& Hadley, F. (2012). Child participation and disaster risk reduction. International Journal of Early Years Education, 20(3), 300-308. doi:https://doi.org/10.1080/09669760.2012.716712

Nguyen, H. T., \& Rydstrom, H. (2018). Climate disaster, gender, and violence: Men's infliction of harm upon women in the Philippines and Vietnam. Women's Studies International Forum, 71, 56-62. doi:https://doi.org/10.1016/j.wsif.2018.09.001

Pillai, R R \& Sekar, K. (2013). Impact of tsunami disaster among children. Dysphrenia, 4(1), 21-24.

Reyes, D. D., \& Lu, J. L. (2015). Gender dimension in disaster situations: A case study of flood prone women in malabon city, metro manila. International Journal of Disaster Risk Reduction, 15, 1-7. doi:https://doi.org/10.1016/j.ijdrr.2015.11.001

Rushton, A., Gray, L., Canty, J., \& Blanchard, K. (2019). Beyond binary: (re)defining "gender" for 21 st century disaster risk reduction research, policy, and practice. International Journal of Environmental Research and Public Health, 16(20), 3984. doi:https://doi.org/10.3390/ijerph16203984

Spindler, H., Elklit, A., \& Christiansen, D. (2010). Risk factors for posttraumatic stress disorder following an industrial disaster in a residential area: A note on the origin of observed gender differences. Gender 
Medicine, 7(2), 156-165.

doi:https://doi.org/10.1016/j.genm.2010.04.001

Thapa, V., \& Pathranarakul, P. (2019). Gender inclusiveness in disaster risk governance for sustainable recovery of 2015 Gorkha Earthquake, Nepal.

International Journal of Disaster Risk Reduction, 34, 209-219. https://doi.org/10.1016/j.ijdrr.2018.11.019

The National Academics. (2012). Disaster resilience: A national imperative. The National Academics Press. doi:https://doi.org/10.1080/00139157.2013.768076

Washington, W. (2018). Child-Centred Risk Reduction Research-into- Gender and Disasters: Considering Children. Global Alliance for Disaster Risk Reduction \& Resilience in the Education Sector, 1-8.

Wooldridge, M. (2015). Postructuralism and Feminism: The Interplay between Gender, Language and. EInternational Relations, 1-25. Retrieved from https://www.e-ir.info/2015/05/22/postructuralism-andfeminism-the-interplay-between-gender-language-andpower/

Young, K. A., Greenbaum, R. T., \& Dormady, N. C. (2017). Sex, gender, and disasters: Experimental evidence on the decision to invest in resilience. International Journal of Disaster Risk Reduction, 24, 1-47. doi:https://doi.org/10.1016/j.ijdrr.2017.06.003

Yumarni, T., Amaratunga, D., \& Haigh, R. (2014). Assessing Gender Vulnerability within Post-earthquake Reconstruction: Case Study from Indonesia. Procedia Economics and Finance, 18, 763-771. doi:https://doi.org/10.1016/s2212-5671(14)01000-4 